\title{
Thermal Analysis of Latent Heat Thermal Energy Storage Systems Enhanced with Annular and Radial Fins
}

\author{
Saeed Tiari ${ }^{1}$, Addison Hockins ${ }^{1}$, Samantha Moretti ${ }^{1}$ \\ ${ }^{1}$ Gannon University \\ 109 University Square, Erie, PA, USA \\ tiari001@gannon.edu; hockins001@gannon.edu; moretti001@gannon.edu
}

\section{Extended Abstract}

A major drawback of latent heat thermal energy storage (LHTES) systems is the low thermal conductivity of phase change materials (PCMs) used as storage media in them. Different passive heat transfer techniques such as using embedded heat pipes [1], impregnation of highly conductive porous media with PCMs [2], dispersion of highly conductive nanoparticles into PCMs [3], and the inclusion of fins into PCMs have been employed to improve the thermal performance of these systems. In the current study, effects of annular and radial fins on the thermal characteristics of a LHTES system during the charging and discharging processes are studied experimentally. Rubitherm RT-55 is used as the phase change material (PCM) and is enclosed within a vertical insulated cylindrical container. The container is manufactured from a $1.27 \mathrm{~cm}$ thick clear acrylic tube with a height of $30.48 \mathrm{~cm}$ and an inner diameter of $17.78 \mathrm{~cm}$. Water is used as the heat transfer fluid (HTF) which is circulated in a copper pipe that passes through the center of the container. For the charging process, hot $\mathrm{HTF}$ at $70{ }^{\circ} \mathrm{C}$ is circulated through the system until the entire mass of solid PCM inside the container is fully molten. For the discharging process, cold $20^{\circ} \mathrm{C} \mathrm{HTF}$ is pumped through the system until all the molten PCM had solidified. Twelve k-type thermocouples are inserted into the PCM container at different heights and depths to monitor the PCM temperature. The inlet and outlet temperature are monitored by two $100 \mathrm{Ohm} \mathrm{RTDs.} \mathrm{The} \mathrm{effects} \mathrm{of} \mathrm{four} \mathrm{different} \mathrm{fin} \mathrm{configurations} \mathrm{attached} \mathrm{to} \mathrm{the} \mathrm{central}$ pipe are studied with the same amount of material used for each configuration. This allows for the understanding of system efficiency while maintaining the same material cost and loss of volume of PCM for energy storage. The two annular fin configurations have fins of $4.0 \mathrm{~cm}$ in length with the first configuration having ten fins with a thickness of $1.58 \mathrm{~cm}$. While the second configuration has twenty fins of thickness $0.79 \mathrm{~cm}$. The two radial configurations are rectangular in shape being $7.77 \mathrm{~cm}$ in length and $22.94 \mathrm{~cm}$ in height. Configuration three has four fins of thickness $1.58 \mathrm{~cm}$ while configuration four has eight fins of thickness $0.79 \mathrm{~cm}$. The effects these fin configurations on the total charging and discharging times as well as the PCM temperature distribution have been studied during charging and discharging cycles. The no-fin benchmark case took 48 hours to fully charge and 42.5 hours to discharge. The 10 annular fins charged the system $84.1 \%$ faster than the nofin case. The 20 annular fin case reduced the charging time by $85.8 \%$. The 10 annular fins decreased discharging time by $68.21 \%$ and the 20 annular fins decreased charging time by $68.58 \%$. The radial fin configurations of four and eight fins were found to decrease the charging time by $81.9 \%$ and $86.6 \%$, respectively. The discharging time was improved by 4 radial fins by $70.0 \%$ and by the 8 radial fins by $80.1 \%$. Overall, it was found for the same amount of fin material, the 8 -fin radial design produces the best results in accelerating the charging and discharging processes.

\section{References}

[1] S. Tiari and S. Qiu. "Three-dimensional simulation of high temperature latent heat thermal energy storage system assisted by finned heat pipes," Energy Conversion and Management, vol. 105, pp. 260-271, November 2015.

[2] S. Tiari and M. Mahdavi. "Computational study of a latent heat thermal energy storage system enhanced by highly conductive metal foams and heat pipes," Journal of Thermal Analysis and Calorimetry, vol. 141, pp.1741-1751, January 2020.

[3] J.M. Khodadadi and S.F. Hosseinizadeh. "Nanoparticle-enhanced phase change materials (NEPCM) with great potential for improved thermal energy storage," International Communications in Heat and Mass Transfer, vol. 34, pp.534-543, May 2007. 